\section{Commentary: Reason for optimism - or the start of a long, dark winter?}

\author{
Gaetano Paone, MD, MHSA
}

With the continued growth of transcatheter aortic valve replacement (TAVR) procedure volume, so too there is an increasing focus on the still-uncertain and evolving treatment algorithm for severe aortic stenosis, especially in younger, lower-risk patients likely to require multiple interventions and devices over their lifetime. ${ }^{1,2}$ For better or worse, much of the decision making is currently driven by patient choice. Recent reports describing the technical challenges and generally suboptimal outcomes of explanting failed TAVR devices from either native or surgical valves have served to validate growing concerns. ${ }^{3-5}$

In this month's Journal, Fukuhara and colleagues ${ }^{6}$ comprehensively describe their experience with 28 patients (4 referred from outside institutions) who underwent either subsequent valve reintervention following primary TAVR (18 patients) or valve-in-valve TAVR (10 patients). Owing mostly to unfavorable anatomy or the need for concomitant procedures, repeat TAVR was undertaken in only 8 of the 28 patients, belying the idea of patients being advised they can undergo repeat TAVR-in-TAVR with any degree of certainty. Importantly, TAVR in previous surgical aortic valve replacement, albeit with small numbers, was 3 times more likely to fail, and mortality among the TAVR explantation group was $15 \%$ ( 3 of 20 ). The authors appropriately advise that "careful assessment of aortic root anatomy and the feasibility of a repeat TAVR procedure should be part of the initial TAVR workup for young patients choosing to

\footnotetext{
From the Division of Cardiothoracic Surgery, Structural Heart and Valve Center, Emory University School of Medicine, Atlanta, Ga.

Disclosures: Dr Paone is a consultant and proctor for Edwards Lifesciences and has equity in Medtronic.

The Journal policy requires editors and reviewers to disclose conflicts of interest and to decline handling or reviewing manuscripts for which they may have a conflict of interest. The editors and reviewers of this article have no conflicts of interest.

Received for publication April 7, 2021; revisions received April 7, 2021; accepted for publication April 9, 2021; available ahead of print April 16, 2021.

Address for reprints: Gaetano Paone, MD, MHSA, Division of Cardiothoracic Surgery, Structural Heart and Valve Center, Emory University Midtown Hospital, 550 Peachtree St NE, Davis-Fischer Bldg, 4th floor, Atlanta, GA 30308 (E-mail: gaetano.paone@emory.edu).

J Thorac Cardiovasc Surg 2023;165:1333-4

$0022-5223 / \$ 36.00$

Copyright (c) 2021 by The American Association for Thoracic Surgery

https://doi.org/10.1016/j.jtcvs.2021.04.023
}

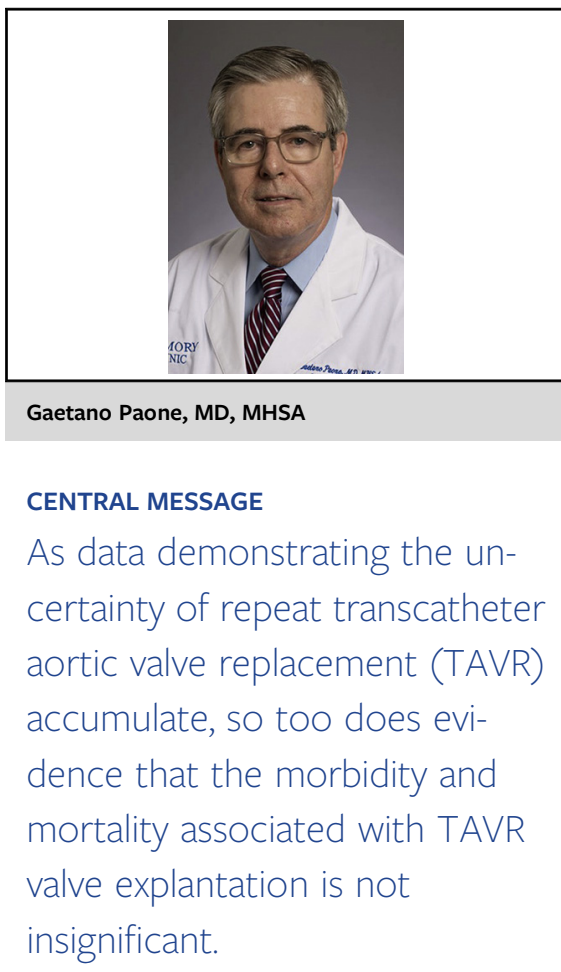

undergo a TAVR procedure" and further suggest at least considering a mechanical prosthesis.

That said, it is unclear if these 28 out of more than 1400 TAVR cases represent a relatively large number or a small number, and thus the extent to which this report can or should inform the algorithm for initial and subsequent valve choice. Center-specific referral bias will almost certainly impact the number of patients presenting for additional procedures, with the true incidence therefore unknown. Also unknown is how many patients who underwent TAVR explantation because they needed concomitant procedures would have needed those same procedures had they initially undergone surgical aortic valve replacement. Or how many, rightly or wrongly, might have, if treated elsewhere, undergone repeat TAVR along with other catheter basedinterventions, such as coronary stenting, transcatheter mitral valve repair, or replacement. Similarly, the use of leaflet splitting techniques (BASILICA) might have allowed repeat TAVR in at least several of those with presumed high risk of coronary obstruction.

As the authors acknowledge, the extensive use of selfexpanding TAVR devices and stentless surgical valves somewhat limits the generalizability of their experience. Nevertheless, the technical challenges and the morbidity and mortality associated with surgical explant demonstrated by this very experienced group should serve as a warning to 
pause and consider these decisions carefully at all stages. Whether the results of valve explantation will improve with more experience in a presumably younger and healthier lower-risk cohort in the future remains to be determined. Should we interpret this report with optimism, or does it portend the coming of a long, dark winter? I suspect we will know soon enough, but clearly the early results are not that encouraging.

\section{References}

1. Carroll JD, Mack MJ, Vemulapalli S, Hermann HC, Gleason TG, Hanzel G, et al. STS-ACC TVT Registry of transcatheter aortic valve replacement. J Am Coll Cardiol. 2020;76:2492-516.

2. Hanzel GS, Gersh BJ. Transcatheter aortic valve replacement in low-risk, young patients: natural expansion or cause for concern? Circulation. 2020;142:1317-9.
3. Fukuhara S, Brescia AA, Shiomi S, Rosati CM, Yang B, Kim KM, et al. Surgical explantation of transcatheter aortic bioprostheses: results and clinical implications. J Thorac Cardiovasc Surg. January 12, 2020 [Epub ahead of print].

4. Brescia AA, Deeb GM, Wai Sang SL, Tanaka D, Grossman PM, Sukul D, et al. Surgical explantation of transcatheter aortic valve bioprostheses: a statewide experience. Circ Cardiovasc Interv. 2021;14:e009927.

5. Jawitz OK, Gulack BC, Grau-Sepulveda MV, Matsouaka RA, Mack MJ, Holmes DR Jr, et al. Reoperation after transcatheter aortic valve replacement: an analysis of the Society of Thoracic Surgeons database. JACC Cardiovasc Interv. 2020;13:1515-25

6. Fukuhara S, Nguyen CTN, Kim KM, Yang B, Ailawadi G, Patel HJ, et al. Aortic valve reintervention after transcatheter aortic valve replacement. J Thorac Cardiovasc Surg. 2023;165:1321-32.e4.

7. Lederman RJ, Babaliaros VC, Rogers T, Khan JM, Kamioka N, Dvir D, et al. Preventing coronary obstruction during transcatheter aortic valve replacement: from computed tomography to BASILICA. JACC Cardiovasc Interv. 2019;12: $1197-216$. 